\title{
The Fine Structure of Safflower (Carthamus tinctorius L.) Chromosomes as Revealed by Pachytene Analysis
}

\author{
Anjali Malik ${ }^{1, *}$ and Anand Kumar Srivastava ${ }^{2}$ \\ ${ }^{1}$ Department of Microbiology, C.C.S. University, Meerut 250 004, India \\ ${ }^{2}$ Department of Botany, C.C.S. University, Meerut 250 004, India
}

Received May 26, 2009; accepted August 31, 2009

\begin{abstract}
Summary The 7 accessions of Carthamus tinctorius from different locations were analyzed in detail for establishing the chromosome and karyotype polymorphism. All 12 pachytene chromosomes were clearly identified on the basis of length, arm ratio, centromeric index, symmetry index, total chromatin length and Percent chromomere per chromosome. The karyotype and heterochromatin distribution patterns reported in this study provide a foundation toward cytological characterization of the Carthamus genome. The chromosome size ranges between $546.53 \mu \mathrm{m}$ to $933.53 \mu \mathrm{m}$. Variability within the individual chromosomes with respect to the size, shape and position of the centromere was found to be well marked. Chromosomes were arranged from 1 to 12 following a descending order of length. At pachytene, the pollen mother cells have 12 bivalents and prominent nucleolus. The accessions exhibited significant variability in their pachytene chromosome characteristics.
\end{abstract}

Key words Carthamus, Pachytene karyotype, Centromere, Heterochromatin distitribution.

The genus Carthamus L. is a member of the family Asteraceae, and comprises more than 20 species with varying chromosome numbers $2 n=20$ to $2 n=64$. Carthamus tinctorius, commonly called as Safflower, is the only cultivated species of this genus. The species is fast gaining importance as an oil crop. Earlier, this species was cultivated for extracting dye for food and cloth. Modern researches have shown that Safflower oil can reduce coronary heart disease by lowering cholesterol levels. The somatic chromosome analysis of the genus Carthamus is very difficult due to poor stainability, stickiness and tendency of chromosomes to overlap at metaphase and diffused appearance of primary and secondary constrictions of the chromosomes. Usefulness of the pachytene stage of meiosis for studying detailed morphology of the chromosome was first emphasized by McClintock (1931). It is the stage of meiosis I, in which complete pairing of chromosomes and lining up of the chromomeres takes place and synapsis is at its climax.

The pachytene analysis in accessions of the genus Carthamus has been conducted in the present study.

\section{Materials and methods}

Seven accessions of Carthamus tinctorius from different locations were explored for the details of pachytene karyotype (Table 1). Young floral buds were collected and fixed in Carnoy's fluid II (6:3:1=absolute ethanol: chloroform: glacial acetic acid) for $24 \mathrm{~h}$ and stored in $70 \%$ ethanol in refrigerator. Anthers were squashed and smeared in $1.5 \%$ aceto-carmine.

All the observations and photomicrographs were taken from squashed temporary preparations. Only well spread pollen mother cells were considered for detailed studies. Chromosome measurements were made on the enlarged prints and converted to micrometers by relating

\footnotetext{
*Corresponding author, e-mail: anjali_malik7@hotmail.com
} 
Table 1. List of accessions used for pachytene chromosomes analyses

\begin{tabular}{ccll}
\hline \hline S. No. & Lab Code & \multicolumn{1}{c}{ Species } & Source country \\
\hline 1. & $\mathrm{~T}-27$ & Carthamus tinctorius & China \\
2. & $\mathrm{~T}-28$ & Carthamus tinctorius & China, Beijing \\
3. & $\mathrm{~T}-30$ & Carthamus tinctorius & China, Hunan \\
4. & $\mathrm{~T}-32$ & Carthamus tinctorius & Czechoslovakia \\
5. & $\mathrm{~T}-33$ & Carthamus tinctorius & Ethiopia \\
6. & $\mathrm{~T}-34$ & Carthamus tinctorius & Former Soviet Union \\
7. & $\mathrm{~T}-47$ & Carthamus tinctorius & India, Delhi \\
\hline
\end{tabular}

Table 2. Data related to pachytene karyotype of Carthamus accessions/species

\begin{tabular}{ccccccccc}
\hline \hline Code & Accessions & TLCC & TLLA & TLSA & GI & SI & TCL & KF \\
\hline T-27 & C. tinctorius & 746.76 & 411.13 & 335.63 & 39.25 & 81.64 & 259.72 & $\mathrm{KF}=16 \mathrm{D}(\mathrm{m})+2 \mathrm{D}(\mathrm{M})+6 \mathrm{E}(\mathrm{m})$ \\
$\mathrm{T}-28$ & C. tinctorius & 546.53 & 306.59 & 239.94 & 22.86 & 78.26 & 279.93 & $\mathrm{KF}=8 \mathrm{D}(\mathrm{m})+12 \mathrm{E}(\mathrm{m})+4 \mathrm{E}(\mathrm{sm})$ \\
$\mathrm{T}-30$ & C. tinctorius & 568.46 & 312.61 & 255.85 & 29.41 & 81.84 & 492.35 & $\mathrm{KF}=12 \mathrm{D}(\mathrm{m})+10 \mathrm{E}(\mathrm{m})+2 \mathrm{E}(\mathrm{M})$ \\
$\mathrm{T}-32$ & C. tinctorius & 817.00 & 436.45 & 380.55 & 45.24 & 87.19 & 301.00 & $\mathrm{KF}=20 \mathrm{D}(\mathrm{m})+2 \mathrm{E}(\mathrm{M})+2 \mathrm{E}(\mathrm{m})$ \\
$\mathrm{T}-33$ & C. tinctorius & 791.20 & 421.40 & 369.80 & 11.11 & 87.76 & 462.25 & $\mathrm{KF}=2 \mathrm{~B}(\mathrm{~m})+12 \mathrm{D}(\mathrm{m})+8 \mathrm{E}(\mathrm{m})+2 \mathrm{E}(\mathrm{M})$ \\
$\mathrm{T}-34$ & C. tinctorius & 625.65 & 328.95 & 296.70 & 25.00 & 90.20 & 299.28 & $\mathrm{KF}=12 \mathrm{D}(\mathrm{m})+2 \mathrm{D}(\mathrm{M})+8 \mathrm{E}(\mathrm{M})+2 \mathrm{E}(\mathrm{m})$ \\
$\mathrm{T}-47$ & C. tinctorius & 933.53 & 504.39 & 429.14 & 11.93 & 85.08 & 331.10 & $\mathrm{KF}=2 \mathrm{~B}(\mathrm{M})+2 \mathrm{~B}(\mathrm{~m})+16 \mathrm{D}(\mathrm{m})+4 \mathrm{E}(\mathrm{m})$ \\
\hline
\end{tabular}

measurements made in the microscope with a micrometer. Pachytene karyotype analysis was based on at least 5 high-quality prophase cell plates. The following parameters were used for the pachytene karyotype analyses.

Details of karyotype were analyzed for (a) Total length of the chromosome of a complement (TLCC), (b) Length of long and short arms and the whole chromosome, (c) Arm's ratio (AR), (d) Total length of all short arms (TLSA), (e) Total length of all long arms (TLLA), (f) Centromeric index (ci), (g) Gradient index (GI), (h) Symmetry index (SI), (i) Total chromatin length (TCl\%) and (j) Percent chromomere per chromosome (CPC\%).

Arm's ratio, $\mathrm{Ci}$, GI, SI, TCl\%, and CPC\% were worked out by using the formulae given below.

$$
\begin{array}{ll}
\text { Arm's ratio } & =\frac{\text { Length of long arm of a chromosome }}{\text { Length of short arm of a chromosome }} \\
\text { Ci } & =\frac{\text { Length of short arm of a chromosome }}{\text { Total length of the chromosome }} \times 100 \\
\text { GI } & =\frac{\text { Length of shortest chromosome of the complement }}{\text { Length of longest chromosome of the complement }} \times 100 \\
\text { SI } & =\frac{\text { Total length of all short arms }}{\text { Total length of all long arms }} \times 100 \\
\text { TCl } \% & =\frac{\text { Total length of a chromosome pair }}{\text { Total length of the gametophytic chromosome set }} \times 100
\end{array}
$$

CPC\% was worked out by using following formula.

$$
\mathrm{CPC} \%=\frac{\text { Total amount of chromosome in long and short arm }}{\text { Total length of long and short arm }} \times 100
$$



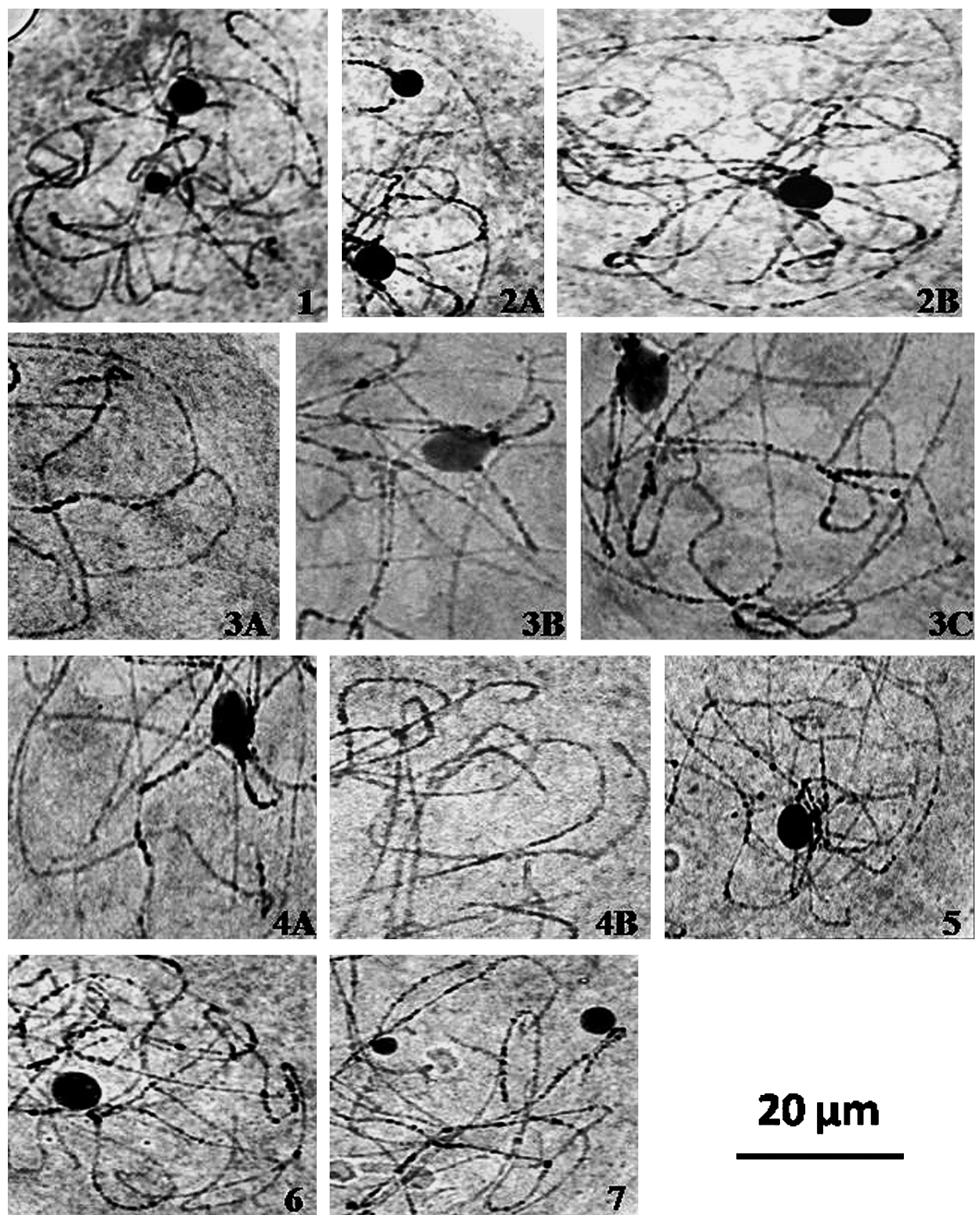

\section{$20 \mu \mathrm{m}$}

Figs. 1-7. Photomicrographs showing pachytene chromosomes in different Carthamus accessions. (1) T-27 (2A-2B) T-28 (3A-3C) T-30 (4A-4B) T-32 (5) T-33 (6) T-34 (7) T-47.

Results and discussion

At pachytene, the pollen mother cells have 12 bivalents and prominent nucleolus. The chromosomes are long and intertwined. For analysis of the pachytene karyotype, the parameters listed with materials and methods were analyzed. Data pertaining to the pachytene karyotype analyses are listed in Table 2. This table contains karyotype formulae based on pachytene analysis. The chromosome size ranges between $546.53 \mu \mathrm{m}$ to $933.53 \mu \mathrm{m}$. The pachytene chromosomes of the complement were arranged on the basis of the total length into 5 types, $A-E(A=250-200 \mu \mathrm{m}$, $\mathrm{B}=200-150 \mu \mathrm{m}, \mathrm{C}=150-100 \mu \mathrm{m}, \mathrm{D}=100-50 \mu \mathrm{m}, \mathrm{E}=<50 \mu \mathrm{m})$. The pachytene chromosome were further divided into different categories as per Levan et al. (1964) on the basis of arm ratio $(\mathrm{M}=1.0$, 
$\mathrm{m}=1.0-1.7, \mathrm{sm}=1.7-3.0$ ). Most of the pachytene chromosomes were of ' $\mathrm{m}$ ' and ' $\mathrm{M}$ ' type. However, 'sm' type chromosomes were also present in low frequency in T-28.

Only selected photomicrographs of typical pollen mother cell showing pachytene chromosomes are presented in Figs. 1-7 because pollen mother cells were large. Total amount of chromomere present in the total length of the long and short arms of the gametophytic set of pachytene chromosomes of all the 7 accessions are graphically represented in Fig. 8.

Idiograms of the pachytene chromosomes are presented in Figs. 9-15. The accessions differed significantly in the length of long and short arms of the same sets, chromomere distributions in various chromosomes of the same set and different sets, total length of long and short arms of a

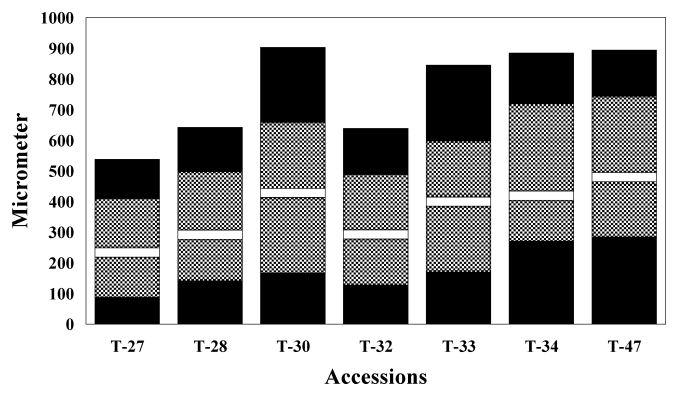

Fig. 8. Graphical representation of total amount of chromomeres present in total length of long and short arms of the pachytene chromosomes. chromosome set and total amount of chromomeres present in a set of chromosomes.

Cytogenetic studies of higher eukaryotic genomes are based on reliable and easy-to-use techniques for chromosome identification. The details of pachytene karyotype were analyzed using the parameters as per Srivastava and Purnima (1990) and Srivastava and Kalra (1996). The somatic chromosome of the species of the genus Carthamus are difficult to resolve due to poor stainability, stickiness and tendency to overlap at metaphase. The centromeric portions and the secondary constrictions
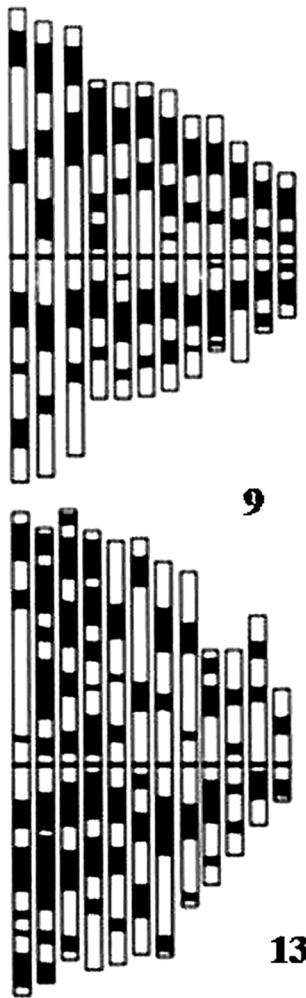

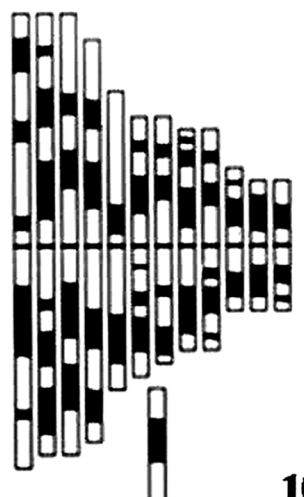

10

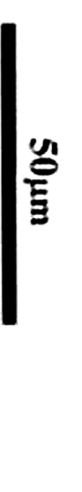

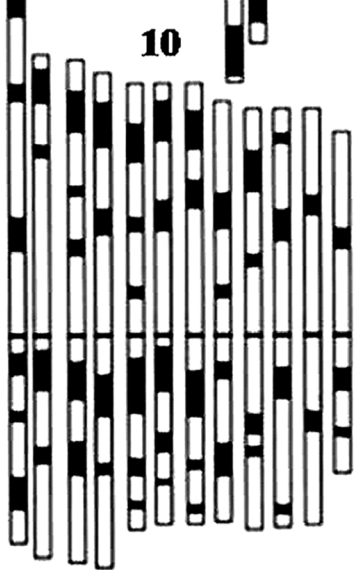
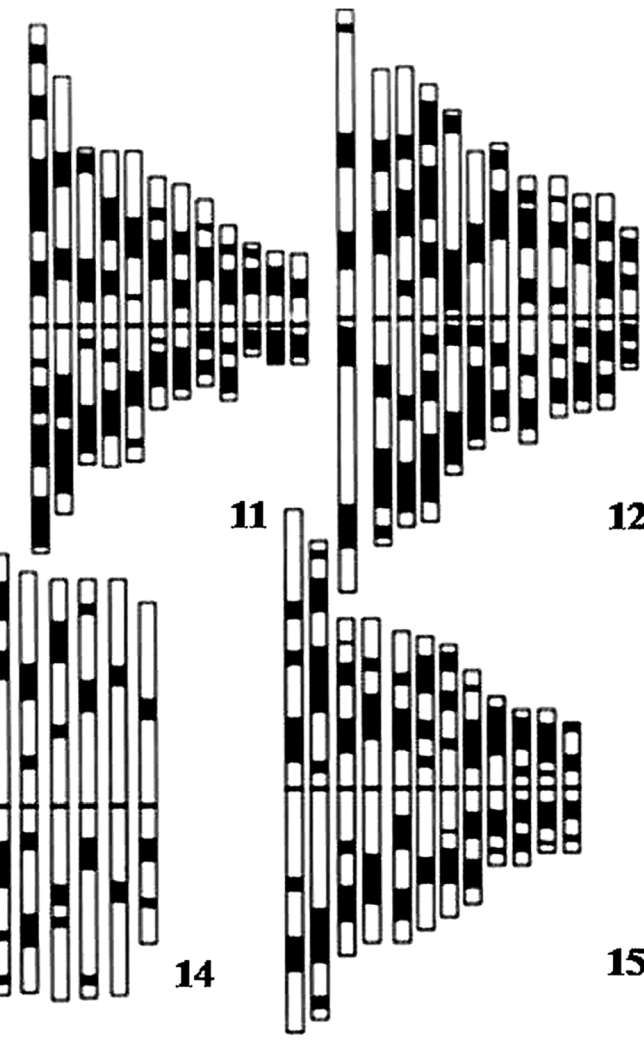

Figs. 9-15. Idiograms of the pachytene chrosomes of different accessions of Carthamus. (9) T-27 (10) T-28 (11) T-30 (12) T-32 (13) T-33 (14) T-34 (15) T-47. 
are not easily recognizable (Ashri and Knowles 1960, Estilai and Knowles 1980, Pillai et al. 1981, Jayaramu and Chatterji 1986, Kumar 1991). Because of this the karyotype analyses in the genus Carthamus has been undertaken scantily in the past. Pachytene studies have an edge over somatic karyology for the purpose of chromosome identification. This is because at this stage chromosomes are relatively less condensed and therefore reveal their structural landmarks more easily. This karyotype is anchored by centromere-specific and chromosomal arm-specific cytological landmarks. The karyotype and heterochromatin distribution patterns reported in this study provide a foundation toward cytological characterization of the Carthamus genome. On account of these advantages, they have been employed for identification in a variety of angiosperms e.g. maize (McClintok 1931, Rhoades and McClintock 1935), tomato (Barton 1950, Rick and Barton 1954), rye (Lima-De-Faria 1952), barley (Sarvella et al. 1958), rice (Sen 1965, Khush et al. 1984) and Castor (Paris et al. 1935) etc. The accessions differed significantly in the length of long and short arms of the same set and different sets, total length of long and short arms of a chromosome set and total amount of chromomeres present in a set of chromosome. The comparison of pachytene karyotype related to all these accessions indicates that all the accessions do differ in their pachytene karyotype. To the best of our knowledge the pachytene analysis in accessions/species of the genus Carthamus has been conducted for the first time. The length of the chromosome and distribution pattern of chromomeric segments exhibits remarkable differences between chromosomes of a complement and between the chromosome complements of different accessions of Carthamus.

\section{Acknowledgements}

The senior author is grateful to Prof. (Dr.) A. K. Srivastava, Head Department of Botany C.C.S. University Meerut, for providing the necessary facilities to carry out the work.

\section{References}

Ashri, A. and Knowles, P. F. 1960. Cytogenetics of safflower (Carthamus L.) species and their hybrids. Agron J. 52: 11-17. Barton, D. W. 1950. Pachytene morphology of the tomato chromosome complement. Amer J. Bot. 37: 639-643.

Estilai, A. and Knowles, P. F. 1980. Aneuploids in safflower. Crop Sci. 20: 516-518.

Jayaramu, M. and Chatterji, A. K. 1986. Karyological studies on Indian wild safflower Carthamus oxycantha M.B. Karyologia 39: 179-184.

Khush, G. S., Singh, R. J. Sur, S. C. and Librojo, A. L. 1984. Primary trisomics of rice: Origin, morphology, cytology and uses in linkage mapping. Genetics 107: 141-163.

Kumar, H. 1991. Cytogenetics of Safflower. In: Gupta, P. K. and Tsuchiya, T. (eds.) Chromosome Engineering in Plants second edition, Elsevier Science Publishing Company, Amsterdam, pp. 251-278.

Levan, A., Fredgra, K. and Samber, A. A. 1964. Nomenclature for Centromeric Position on Chromosomes. Hereditas 52: 201-220.

Lima-De-Faria, A. 1952. Chromosome analysis of the chromosome complement of rye. Chromosoma 5: 1-68.

McClintok B. 1931. Cytological observation of deficiencies involving known genes, translations and an inversion in Zeamays. Miss Agric Exp Stat Bull 163: 1-30.

Paris, H. S., Shifriss, O. and Jelenkovic, G. J. 1935. Idiograms of Ricinus communis. J. Hered 69: 191-196.

Pillai, R. S. N., Kumar, H. and Singh, R. B. 1981. Karyotype analysis of safflower. Crop Sci. 27: 809-811.

Rhoades, M. M. and McClintock, B. 1935. The cytogenetics of maize. Bot. Rev. J. 1: 292-325.

Rick, C. M. and Barton, D. W. 1954. Cytological and genetical identification of the primary trisomics of the totmato Genetics 39: 640-644.

Sarvella, P., Homelgren, J. B. and Nilan, R. A. 1958. Analysis of barley pachytene chromosome. Nucleus 1: $183-204$.

Sen, S. K. 1965. Cytogenetics of trisomics in rice. Cytologia 30: 229-238.

Srivastava, A. K. and Purnima 1990. Numerical and structural inconstancy in Belamchanda chinensis DC (Iridaceae). Proc. Indian Acad Sci. 100: 205-210.

Srivastava, A. K. and Kalra R. 1996. Three dimensional analysis of karyotypes in Carthamus. J. Cytol. Genet. 31: $139-144$. 